\title{
Effects of Poly-herbal Tablet as Herbal Medicine on Lipid Level
}

\author{
Woro Rukmi Pratiwi1* ${ }^{*}$ Eti Nurwening Sholikhah¹, Dwi Aris Agung Nugrahaningsih1, Mia \\ Munawaroh Yuniyanti², Mustofa1, Ngatidjan' \\ ${ }_{1}^{1}$ Department of Pharmacology and Therapy, Faculty of Medicine, Public Health and Nursing, Universitas Gadjah Mada, \\ Yogyakarta \\ ${ }^{2}$ Student of Faculty of Medicine, Public Health and Nursing, Universitas Gadjah Mada, Yogyakarta
}

\begin{abstract}
Dyslipidemia is one of the high-risk factors that cause cardiovascular disease and the prevalence is increasing all the time. Garlic (Alii sativi) has been suggested to reduce serum lipid level. Poly-herbal is herbal medicine that has been widely used in Indonesia, and it contains Alii sativi, Belericae fructus, Curcumae aeroginosae, and Amomi fructus extract. This study aimed to evaluate the effects of poly-herbal tablet on lipid levels in dylipidemia subjects. The study was conducted for 6 weeks on 58 dylipidemia subjects. Subject was divided into 2 groups. Group 1 was given Poly-herbal with the dose 2x1200 mg, and the group 2 was not given anti-dyslipidemic drugs (control group). Serum lipid level (total cholesterol, LDL, HDL, and triglycerides) were checked before the treatment (H0) and after the treatment (M6). There was a significant difference on the reduction of serum lipids level between the group that given Poly-herbal vs control group, respectively total cholesterol $(-12.04 \pm 3.2$ vs $8.38 \pm 4.3 ; p=.000)$, LDL $(-4.42 \pm 2.8$ vs $6.93 \pm 4.7$; $\mathrm{p}=.049)$ and HDL $(-2.62 \pm 1.0$ vs 3.31 $\pm 1.4 ; \mathrm{p}=.005)$. Triglyceride level on Poly-herbal group is not significantly decreased. In Poly-herbal group there was also a decrease in HDL levels which was not statistically significant $(-2.62 \pm 1, \mathrm{p}=.015)$. This is probably due to the HDL baseline in the control group included in the normal HDL category $(57.38 \pm 14.9)$ so that the HDL levels after being given treatment did not increase. This study suggests that using Poly-herbal in dylipidemia subjects can reduce the level of total cholesterol and LDL.
\end{abstract}

Keywords: Dyslipidemia, garlic, lipids level, herbal medicine

\section{INTRODUCTION}

Cardiovascular disease due to atherosclerosis is the most common cause of death in the world. WHO states that there are 17.9 million people/year dying from cardiovascular disease, with $>75 \%$ of deaths occurring in middle and lowincome countries (WHO, 2018). There are risk factors for cardiovascular disease that can be modified and cannot be modified. One risk factor that can be modified is dyslipidemia (Hajar, 2017). Dyslipidemia is defined as an abnormality of serum blood lipid levels, with the parameters are total cholesterol, LDL, HDL and triglycerides (Adam, 2017).

The main treatment for dyslipidemia is lifestyle modification. However, many patients fail to control lipid levels only with this treatment because patients cannot change their eating habits yet. So that drug intervention is needed to control the patient's lipid levels. Garlic is one of the popular herbal ingredients developed for complementary medicine. Several studies have shown that garlic has several therapeutic effects on cardiovascular risk factors, such as dyslipidemia, hypertension,

\footnotetext{
*Corresponding author : Woro Rukmi Pratiwi

Email : wororukmi@ugm.ac.id
}

diabetes and obesity (Hosseini and Hosseinzadeh, 2015; Sobenin et al., 2008; Varshney and Budoff, 2016). The effects of garlic on dyslipidemia through several mechanisms, such as inhibiting cholesterol biosynthesis, reducing lipid and fibrinogen levels, decreasing LDL oxidation, increasing fibrinolytic activity, lowering blood pressure and inhibiting the progression of coronary artery calcification on dosage $300 \mathrm{mg}$ three times a day (Sahebkar et al., 2016). Components in garlic that have shown benefits include allicin $((R, S)$ diallyldisulfid-S-oxide), S-allylcysteine (SAC), ajoene, diallyl disulfide, SAC sulfoxide and S-methylcysteine sulfoxide (Jung et al., 2014). Belericae fructus and Amomi fructus have also been shown to have antidyslipidemic effects (Azis et al., 2013; Lu et al., 2018).

Poly-herbal is one of the herbal medicines that has been used widely in Indonesia. Poly-herbal contains several herbal ingredients such as Alii sativi (garlic), Belericae fructus, Curcumae aeroginosae and Amomi fructus extract. From the facts above, This study aimed to evaluate the effects of poly-herbal tablet on lipid levels in dylipidemia subjects. 


\section{METHODOLOGY Subjects}

Subjects who participated in this study were dyslipidemic people with the inclusion criteria were adult, men and women 20-65 years old, fulfilling the diagnostic criteria: total cholesterol> $200 \mathrm{mg} / \mathrm{dL}$ or LDL $>100 \mathrm{mg} / \mathrm{dL}$ or $\mathrm{HDL}<50 \mathrm{mg} / \mathrm{dL}$ or triglycerides $>150 \mathrm{mg} / \mathrm{dL}$, new or old dyslipidemic patient who 14 days before the recruitment did not take anti-dyslipidemia or herbal drugs to reduce serum lipid levels and were willing to take part in the study by signing an informed consent. Pregnant/breastfeeding mothers and patients with a history of diabetes or heart disease who have liver function abnormalities (SGOT and/or SGOT $\geq 3$ times the upper limit of normal values), have kidney function abnormalities (ureum and/or creatinine $\geq 3 \mathrm{mg}$ / $\mathrm{dL}$ ) and patients with hypersensitivity or intolerance to Poly-herbal was excluded in this study.

\section{Methods}

This study was a 6-week, randomized, placebo-controlled trial (natural history group). This study has received the ethic feasibility reference (KE/FK/0234/EC/2018) from the Medical and Health Research Committee (MHREC) Faculty of Medicine of University Gadjah Mada_DR.Sardjito General Hospital. Subjects who meet the criteria would take an initial examination (physical examination, ECG and laboratory examination). After that the subjects would be divided into 2 groups, the first group was the group given 2x1200 mg Poly-herbal, and the second group was the group not given the antidyslipidemia drugs (control group).

\section{Procedures}

Fifty eight subjects were divided into 2 groups, group 1 were subjects who were given Poly-herbal with the dose 2x $1200 \mathrm{mg}$ for 6 weeks and group 2 were subjects who were not given anti-dyslipidemic drugs (control group). Polyerbal preparations in figuret form with the strength was $600 \mathrm{mg}$. Poly-herbal was taken twice with an interval of 12 hours. Took at the same time, between 07.00-09.00 and 19.00-21.00, before or after meals. Examinations performed were physical, ECG and laboratory tests. Laboratory examinations include routine blood tests, lipid levels, liver function and kidney function. Examination was done twice, at the time before treatment (H0) and after the treatment was complete (M6). Blood sampling was done after the subject was fasting for at least 6 hours. The lipid parameters measured were total cholesterol, LDL,
HDL, and triglycerides. Patients must consult other drugs consumed during the study. Drugs that were allowed to be consumed were drugs that do not affect lipid levels. If there were complaints or side effects, the patient was asked to report.

\section{RESULTS AND DISCUSSION}

The study was conducted in April-October 2018 in Plosokuning, Kancilan, Kronggahan, Denokan, Setan, Senoboyo, Kayen, Meguwo and Barongan. A total of 58 subjects participated in this study and were divided into 2 groups, 29 subjects were given Poly-herbal with a dose of $2 \times 1200 \mathrm{mg}$, 29 subjects were not given anti-dyslipidemia drugs (control group). On the first day after administration of therapy, there were 2 subjects who dropped out in the Poly-herbal group because the subject complained of nausea. In the second week, there was 1 subject who dropped out because of self-discontinued intervention. So that the subjects who participated until the end of the study were 55 people (26 subjects in the Polyherbal group and 29 subjects in the control group).

Baseline characteristics of the subjects are presented in (Table I). There were no significant differences between the two groups on the characteristics of age, sex, systolic and diastolic blood pressure, total cholesterol, HDL, LDL and triglycerides.

The difference in lipid level changes in the sixth week between the Poly-herbal group and the control group can be seen in (Table II). The parameters of total cholesterol, LDL and HDL were significantly different between the Poly-herbal group compared to the control group ( $p=.000$, $p=.049, p=.005$ respectively). Whereas there was no significant difference in changes in triglyceride levels between the Poly-herbal vs control groups.

The results of this study showed that total cholesterol, LDL and triglyceride levels decreased after administration of garlic extract for 6 weeks. This is a good agreement with Hussein et al., (2013) that the level of total cholesterol, LDL, and triglycerides are decreased on the subject that given extracts with the dose of $500 \mathrm{mg}$ twice a day. A series of experiments have been conducted to examine the effects of garlic in animal studies (Ebrahimi et al., 2015; Ha et al., 2015; Perez-Torres et al., 2016; Ragavan et al., 2017). Summarizes a number of animal studies in the literature, from which we can include garlic preparations usually displayed positive effects. The mechanism of action of garlic that has been known to reduce lipid levels in experimental animals is by reducing cholesterol absorption in the intestine, inhibiting enzymes that play a role in cholesterol biosynthesis, and deactivating 3- hydroxy- 3- methylglutaryl- CoA 
Table I. Baseline Characteristics

\begin{tabular}{|c|c|c|c|}
\hline Characteristics & Poly-herbal group (n=26) & Control group $(n=29)$ & $p$-value \\
\hline \multicolumn{4}{|l|}{ Age (years) } \\
\hline Mean (SD) & $52.89(6.8)$ & $51.10(8.1)$ & .385 \\
\hline Range & $41-66$ & $29-65$ & \\
\hline \multicolumn{4}{|l|}{ Gender (\%) } \\
\hline Male & $11.54 \%$ & $27.59 \%$ & .137 \\
\hline Female & $88.46 \%$ & $72.41 \%$ & \\
\hline \multicolumn{4}{|c|}{ Systolic Blood Pressure (mmHg) } \\
\hline Mean (SD) & $150.87(9.9)$ & $153.79(9.8)$ & .276 \\
\hline Range & $140-180$ & $140-180$ & \\
\hline \multicolumn{4}{|c|}{ Diastolic blood pressure (mmHg) } \\
\hline Mean (SD) & $94.62(9.0)$ & $97.24(9.6)$ & .303 \\
\hline Range & $70-110$ & $80-120$ & \\
\hline \multicolumn{4}{|c|}{ Total Cholesterol (mg/dL) } \\
\hline Mean (SD) & $215.23(16.8)$ & $210.45(45.1)$ & .598 \\
\hline Range & $164-252$ & $142-336$ & \\
\hline \multicolumn{4}{|l|}{ HDL (mg/dL) } \\
\hline Mean & $57.38(14.9)$ & $47.00(11.3)$ & .005 \\
\hline Range & $30-94$ & $13-77$ & \\
\hline \multicolumn{4}{|l|}{ LDL (mg/dL) } \\
\hline Mean & $143.38(15.8)$ & $144.55(45.3)$ & .897 \\
\hline Range & $100-177$ & $66-277$ & \\
\hline \multicolumn{4}{|l|}{ Triglycerides (mg/dL) } \\
\hline Mean & $133.88(137.7)$ & $168.21(149.8)$ & .382 \\
\hline Range & $50-773$ & $69-876$ & \\
\hline
\end{tabular}

reductase (HMG-CoA reductase), which also plays a role in cholesterol biosynthesis (Khoo and Aziz, 2009). The substance of garlic which is thought to play a role in reducing lipid levels is Allicin. Allicin is one of the sulfur components in garlic produced from the interaction between the allinase enzyme and the alliin substrate when the garlic is broken down (Lu et al., 2012; Zeng et al., 2012). On in vitro study, there are other organosulfur components besides Allicin which are thought to act as potent inhibitors in cholesterol synthesis, that are Sallylcysteine (SAC) and diallyl-di-sulfide (DAADS) (Hosseini and Hosseinzadeh, 2015). Other components of Poly-herbal has also been studied for their effects on lipid levels. Research conducted by Saravanan et al., (2007) in hypercholesterolemic rats, Belericae fructus preparations can reduce total cholesterol, LDL-C, and triglyceride levels at a dose $1 \mathrm{~g} / \mathrm{kgBW}$. Other studies on animal models also showed similar results (Aziz et al., 2013; Shaila et al., 1998). Mechanism of action of Belericae fructus is thought to inhibit lipid biosynthesis and reduce the absorption of cholesterol in the intestine. Another study by Lu et al., (2018) showed that the effects of Amomi fructus on dose $16 \mathrm{mg} / \mathrm{kgBB}$ in rats that given high-fat diet can inhibit endogenous lipid synthesis, reduce the accumulation of total cholesterol and triglycerides and regulate LDL-C expression. The components of Polyherbal, Curcuma aeruginosa, has not been carried out research to see the hypolipidemic effect in either animals or humans. So the mechanism of action of Poly-herbal is hypothesized by inhibiting cholesterol biosynthesis.

Another study showed results similar to the results of this study. The meta-analysis conducted by Sun et al., (2018) and Ried et al., (2013) found that there was a significant decrease in total cholesterol and LDL in the group treated with garlic compared to controls, whereas triglyceride levels did not decrease significantly. In this study, there were also significant differences between the garlic given groups compared to controls in decreasing total cholesterol and LDL levels, whereas in triglyceride levels there were no significant differences between the two groups. These results probably indicate that garlic has a greater role in reducing total cholesterol and LDL compared to triglycerides.

Other results from this study were that HDL levels in the group given Poly-herbal 2x1200 $\mathrm{mg} /$ days decreased in the sixth week. In this group, there was also a decrease in HDL levels which was not statistically significant $(-2.62 \pm 1, p=.015)$. This is probably due to the HDL baseline in the control 
Tabel II. Reduction of Lipid Level Between Poly-herbal vs Control Group

\begin{tabular}{|c|c|c|c|c|}
\hline Group & $\mathbf{N}$ & $\begin{array}{c}\text { Mean change of } \\
\text { cholesterol levels (SE) }\end{array}$ & $\begin{array}{l}\text { Mean difference } \\
\text { (SE) }\end{array}$ & $p$-value \\
\hline \multicolumn{5}{|l|}{ Kolesterol total } \\
\hline Poly-herbal & 26 & $-12.04(3.2)$ & \multirow{2}{*}{$-20.41(5.50)$} & \multirow{2}{*}{.000} \\
\hline Control & 29 & $8.38(4.3)$ & & \\
\hline \multicolumn{5}{|l|}{ LDL } \\
\hline Poly-herbal & 26 & $-4.42(2.8)$ & \multirow{2}{*}{$-11.35(5.64)$} & \multirow{2}{*}{.049} \\
\hline Control & 29 & $6.93(4.7)$ & & \\
\hline \multicolumn{5}{|l|}{ HDL } \\
\hline Poly-herbal & 26 & $-2.62(1.0)$ & \multirow{2}{*}{$-5.92(1.79)$} & \multirow{2}{*}{.005} \\
\hline Control & 29 & $3.31(1.4)$ & & \\
\hline \multicolumn{5}{|l|}{ Trigliserida } \\
\hline Poly-herbal & 26 & $-16.15(25.1)$ & \multirow{2}{*}{$-10.05(36.74)$} & \multirow{2}{*}{.785} \\
\hline Control & 29 & $-6.10(26.5)$ & & \\
\hline
\end{tabular}

group included in the normal HDL category (57.38 \pm 14.9 ) so that the HDL levels after being given treatment did not increase. The meta-analysis conducted by Zeng et al., (2013) shows that from several clinical trials on the effects of garlic to lipids levels using dyslipidemic subjects with the doses 1 $\mathrm{g} /$ day. Thus, there is a hypothesis that garlic has more positive effects on subjects with abnormal lipid levels, but this effect does not apply to subjects with normal lipid levels. Research conducted by Turner et al., (2004) on subjects with normal lipid levels who were given garlic powder tablets for 12 weeks showed that there was no significant difference between the garlic group and control group of total cholesterol, LDL and HDL levels. Therefore, the baseline level of the subject is very influenced by the outcome, like HDL levels on this study.

\section{CONCLUSION}

This study suggests that Poly-herbal tablet in dyslipidemia subjects can reduce the level of total cholesterol and LDL.

\section{REFERENCES}

Adam JMF, Dislipidemia. In: Setiati S, Alwi I, Sudoyo AW, Simadibrata M, Setiyohadi B, Syam AF. (eds.) Ilmu Penyakit Dalam. 6th ed, Jakarta: Interna Publishing; 2014. p. 2549-2558.

Aziz N, Mehmood MH, Gilani AH. Studies on two polyherbal formulations (ZPTO and ZTO) for comparison of their antidyslipidemic, antihypertensive and endothelial modulating activities. BMC Complement Altern Med 2013;13(371):1-9.

Ebrahimi T, Behdad B, Abbasi MA, Rabati RG, Fayyaz AF, Behnod V, et al., High doses of garlic extract significantly attenuated the ratio of serum LDL to HDL level in rat-fed with hypercholesterolemia diet. Diagn Pathol. 2015;10(74).

Ha AW, Ying T, Kim WK. The effects of black garlic (Allium sativum) extracts on lipid metabolism in rats fed a high fat diet. Nutr Res Pract. 2015;9(1):30-36.

Hajar R. Risk factors for coronary artery disease: historical perspectives. Heart Views 2017;18(3):109-114.

Hosseini A, Hosseinzadeh $\mathrm{H}$. A review on the effects of Allium sativum (garlic) in metabolic syndrome. J Endocrinol Invest 2015;38(11):1147-1157.

Hussien ZM, Ahmed LT, Hussain QG. Effect of atorvastatin and Garlic on Lipid Profile in Hyperlipidemic Patients. Diyala Journal of Medicine 2013;5(1):63-68.

Jung ES, Park SH, Choi EK, Ryu BH, Park BH, Kim DS et al., Reduction of blood lipid parameters by a 12-wk supplementation of aged black garlic: A randomized controlled trial. Nutrition 2014;30:1034-1039.

Khoo YSK, Aziz Z. Garlic supplementation and serum cholesterol: a meta analysis. J Clin Pharm Ther 2009;34:133-145.

Lu S, Zhang T, Gu W, Yang X, Lu J, Zhao R et al., Volatile oil of Amomum villosum inhibits nonalcoholic fatty liver disease via the gutliver axis. BioMed Res Int 2018; 1-16.

Lu Y, He Z, Shen X, Xu X, Fan J, Wu S et al., Cholesterol-lowering effect of allicin on hypercholesterolemic ICR mice. Oxid Med Cell Longev 2012;1-6.

Perez-Torres I, Torres-Narvaez JC, PedrazaChaverri J, Rubio-Ruiz ME, Diaz-Diaz E, Del Valle-Mondragon $\mathrm{L}$ et.al. Molecules. 2016;21(11).

Ried K, Toben C, Fakler P. Effect of garlic on 
serum lipids:an updated meta-analysis. Nutr Rev 2013;71(5):282-299.

Ragavan G, Muralidaran Y, Sridharan B, Nachiappa GR, Viswanathan P. Evaluation of oil in nano-emulsified form: Optimization and its efficacy in high-fat diet induced dyslipidemia in wistar rats. Food Chem Toxicol 2017;105:201-213.

Sahebkar A, Serban C, Ursoniu S, Banach M. Effect of garlic on plasma lipoprotein(a) concentrations: A systematic review and meta-analysis of randomized controlled clinical trials. Nutrition 2016;32:33-40.

Saravanan S, Srikumar R, Manikandan S, Parthasarathy NJ, Devi RS. Hypolipidemic effect of Tripala in experimentally induced hypercholesteremic rats. Yakugaku Zasshi 2007;127(2):385-388.

Shaila HP, Udupa SL, Udupa AL. Hypolipidemic activity of three indigenous drug in experimental induced atherosclerosis. Int J Cardiol 1998;67:119-124.

Sobenin IA, Andrianova IV, Demidova ON, Gorchakova T, Orekhov AN. Lipid lowering effects of time-released garlic powder tablets in double-blinded placebocontrolled randomized study. J Atheroscler Thromb 2008;15(6):334-338.

Sun YE, Wang W, Qin J. Anti-hyperlipidemia of garlic by reducing the level of total cholesterol and low-density lipoprotein: a meta analysis. Medicine 2018;97(18):1-8.

Turner B, Molgaard C, Marckmann P. Effect of garlic (allium sativum) powder tablets on serum lipids, blood plessure and arterial stiffness in normo-lipidaemic volunteers: a randomized, double-blind, placebocontrolled trial. Br J Nutr 2004;92:701-706.

Varshney R, Budoff MJ. Garlic and heart disease. J Nutr 2016;146(2):1-6.

World Health Organization. Cardiovascular Disease. Available from: https:// www.who.int/cardiovascular_diseases/en/ [Accessed 1st November 2018].

Zeng T, Zhang CL, Zhao XL, Xie KQ. The roles of Garlic on the lipid parameters: a systematic review of the literature. Crit Rev Food Sci Nutr 2013;53:215-230. 